Article

\title{
An Integrated Impact of Blockchain on Supply Chain Applications
}

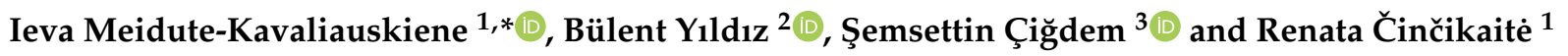 \\ 1 General Jonas Žemaitis Military Academy of Lithuania, Silo St. 5A, LT-10322 Vilnius, Lithuania; \\ Renata.cincikaite@lka.lt \\ 2 Faculty of Economics and Administrative Sciences, Kastamonu University, Kastamonu 37150, Turkey; \\ byildiz@kastamonu.edu.tr \\ 3 Faculty of Economics and Administrative Sciences, Gaziantep University, Gaziantep 27310, Turkey; \\ semsettincigdem@gmail.com \\ * Correspondence: ieva.meidute@lka.lt; Tel.: +370-69986847
}

Citation: Meidute-Kavaliauskiene, I.; Yıldız, B.; Çı̆̆dem, Ş.; Činčikaitè, R. An Integrated Impact of Blockchain on Supply Chain Applications. Logistics 2021, 5, 33. https://doi.org/10.3390/ logistics5020033

Academic Editor: Robert Handfield

Received: 9 April 2021

Accepted: 6 May 2021

Published: 1 June 2021

Publisher's Note: MDPI stays neutral with regard to jurisdictional claims in published maps and institutional affiliations.

Copyright: () 2021 by the authors. Licensee MDPI, Basel, Switzerland. This article is an open access article distributed under the terms and conditions of the Creative Commons Attribution (CC BY) license (https:// creativecommons.org/licenses/by/ $4.0 /)$.

\begin{abstract}
Market conditions have become increasingly dynamic and demanding, resulting in a challenging competitive environment. To adapt to this dynamic environment, supply chains have become increasingly reliant on collaboration, integration, flexibility, and trust between stakeholders. Therefore, the importance of new technological applications in supply chains has grown even more. To improve supply chain flow control, modern specialized applications must be implemented. Blockchain technology has established itself as a necessary component of today's competitive environment. Companies should invest in blockchain technology to respond quickly to changing market conditions and demands in today's dynamic business environment. In this regard, this study investigates the effect of blockchain technology utilization on supply chain transparency, supply chain flexibility, and trust in suppliers. For this purpose, first, data were collected from the first 1000 exporting firms declared in 2019 by the Turkey Exporters Assembly using a survey method. Secondly, factor analyses and regression analyses were performed with the dataset obtained from 84 companies. As a result of the analysis, it was determined that blockchain technology utilization increases transparency, flexibility, and trust in supply chains. According to these results, it is suggested that companies should invest in blockchain technology to make their supply chain more transparent, flexible, and secure. Moreover, blockchain plays a crucial role in building mutual trust with supply chain stakeholders. Finally, the research includes some considerations on the positive implications and potential of blockchain in collaboration and integration.
\end{abstract}

Keywords: blockchain; supply chain transparency; supply chain flexibility; trust; integration; collaboration

\section{Introduction}

Supply chain management is widely regarded as a critical tool for cost control and economic performance improvement in today's competitive business environment. However, given emerging issues such as increasing supply chains' complexity, transparency, and flexibility requirements, task-wise challenges and supply management practices must be modernized if companies and industrial sectors intend to stay competitive [1,2]. Changes in demands and product portfolios cause difficulties in synchronizing the companies' supply and demand plans that make up the supply chain, because they spread to very different geographies [3]. It is essential to prevent any damage to the product that may occur during the transportation of sensitive products from one company to another until they reach the end-users. In traditional supply chain management, tampering of products during transport, delay and fraud, identity verification, lack of data management, and lack of accuracy and integrity of data are common problems [4]. Many large contemporary companies have established their identity systems to protect and maintain the global dominance of their 
operations and retain the authority to instruct their suppliers. Otherwise, they must rely on and adhere to major regulatory firms or intermediaries [1].

Companies have been using information technologies for the optimization of supply chain processes for many years. At first, EDI was used to improve efficiency in communication infrastructure between companies. With EDI integration, companies aimed to achieve benefits such as faster and more efficient data flow [5], shortening order completion times, increasing distribution flexibility, and improving customer service quality [6]. Over time, technologies such as RFID [7] and the internet of things [8] began to be used for needs such as supply chain agility and visibility. Although many digital technology instruments are used to make supply chain processes more efficient today, issues about transparency, flexibility, and trust are still not fully solved. Low transparency in supply chains causes many problems and difficulties in security, traceability, identity documentation, and verification [1]. The relevant literature indicates that establishing a trust-based environment in supply chains remains a significant challenge, and that trust is required for the implementation of effective supply chains [9]. Additionally, demand forecasting becomes more difficult as product life cycles shorten and production lead times lengthen. Supply chains are at risk of overcapacity in this situation due to low demand realization of a lack of product availability. As a result, it is critical to developing flexible supply chains capable of responding quickly to market reactions [1]. Blockchain can solve the issues mentioned above because of its strong characteristics, such as decentralization, transparency, and trust [4]. As an accurate supply chain traceability system, the potential of blockchain to increase the transparency and auditability of material flow will also spread its adoption by supply chains [9]. Using blockchain will help improve supply chain security, traceability, and efficiency. Additionally, blockchain technology can increase collaboration between network members with possible benefits that include decreased costs and increased efficiency. Blockchain technology can also increase customers' trust because it provides traceability of products at all supply chain stages. Furthermore, blockchain technology supports fraud prevention, positively affecting cost reduction and efficiency [10].

Blockchain is a viable method of tracking assets while guaranteeing security and data integrity. The benefits of blockchain-based tracing include the security of information sharing, real-time collection of product data, transparency, and visibility in the supply chain, as well as quality control throughout the entire lifecycle [11]. Many research papers have examined the technology's potential applications in manual or process-intensive roles, such as freight delivery, bill management, and inventory management [12]. It has been emphasized as one of the advantages of blockchain technology to reduce costs by optimizing information flows due to increasing supply chain traceability. Blockchain technology provides these advantages by increasing the level of information sharing and the security of shared information. Moreover, blockchain technology can create more secure supply chains by supporting the weaknesses of other industry 4.0 components (cyber-physical systems, internet of things, etc.) [13].

Due to the reasons listed above, it is inevitable for all companies to follow technology closely and ensure its integration into business processes. Therefore, a new requirement to achieve sustainable competitive advantage and adapt to changing market conditions is to consider the use of digital technologies in supply chain processes in terms of a dynamic market environment.

Companies in Turkey are not an exception in this case. It is vital for Turkish companies that want to gain a strong position in the growing Turkish industrial economy and the international market to adopt a data and information technology-based approach. Technological development provides great advantages to businesses, however it also brings serious risks.

However, the present literature examining blockchain for Turkish companies still has some shortcomings. For example, the available studies are mostly at the theoretical level and empirical studies are quite insufficient. To the best of our knowledge, there is no study, conducted on Turkish firms, which has examined the impact of blockchain technology on 
supply chain transparency, supply chain flexibility, and trust in suppliers in the relevant literature. The vast majority of this information is missing; therefore, we suggest that the following research questions should be investigated:

RQ 1: What kind of relationships exist between blockchain technology and the supply chain dynamics?

RQ 2: Can blockchain technology improve the performance of supply chains by contributing to the creation of more flexible, more transparent, and more reliable supply chains?

RQ 3: What are the possible implications of blockchain technology on supply chain collaboration and supply chain integration? To address these questions, we conceptualize a structural equation model that aims to measure influences of blockchain technology on some critical supply chain dynamics to understand Turkish firms' current situation. These dynamics are trust, transparency, and flexibility. This research will give us a clearer understanding of the effects of blockchain technology on the abovementioned supply chain dynamics.

This paper's content is organized as follows. Section 2 of the study summarizes the pertinent literature on blockchain technology, its relationships to research variables, and the formulation of study hypotheses. Section 3 discusses the sample selection process, the questionnaire, the data collection stages, and the analysis methods used in the study. Section 4 presents the analysis findings with tables and figures. Section 5 discusses the findings, considering the pertinent literature. Finally, Section 6 summarizes the study's implications and limitations and makes some recommendations for future research.

\section{Literature Review and Hypotheses Development}

\subsection{Blockchain Technology}

In the summer of 2008, Nakamoto unveiled the potential of blockchain technology. Nakamoto has completed a bitcoin network transaction among stakeholders [9]. However, blockchain is not limited to cryptocurrency and capital markets. Blockchain technology has wide-ranging applications such as smart contracts, network security, and privacy [14]. Blockchain is a distributed database that stores ever-growing lists of records, given the name of "blocks". Every block is added to the next in the chain, and each transaction is put in a separate block. As a result, the term "blockchain" has arisen from the overall process [15]. Blockchain is a record-keeping system. It stores records regarding transactions shared between stakeholders across all computers in its network. Blockchain is considered a list of interconnected blocks in which each block contains a series of transactions. Each block in the blockchain has both its hash value and that of the previous block (referred to as the master block), and therefore each block is linked back to the master block, forming a "chain" towards the first block [16]. Each transaction in the chain is protected by a digital signature and a cryptographic hash function. The following block establishes a connection with the previous block through its hash [17]. Thus, because multiple nodes manage transaction records, the possibility of changing these records is virtually eliminated. This feature, called immutability, is one of the essential advantages of blockchain of which many industry applications aim to take advantage [9].

Blockchain was first seen in the cryptocurrency market, where this technology was expected to support transactions but has since performed better than predicted in this area and is expanding to other areas. Regarding the key features of blockchain technology, it should be noted that each block has a unique hash (hash, check, account, address hash) number and also carries the hash of the previous block. Another essential feature is that the timestamp is present, which is to record the blocks' duration. Recording the transaction date and time provides integrity, stability, security, and reliability, among other features [18]. Real-time databases with self-generated infrastructure run on a distributed peer-to-to-peer network and handle operations within minutes with mathematical algorithms. This form of identification does not require the use of third-party verification [15]. In the blockchain, verification is decentralized and is carried out through the nodes connected to each block. A node is a client with a copy of the blockchain and can add data to the current block. To 
sign a transaction on the blockchain, a public key and a private key are generated for each user [17].

Collaborative environments are often based on trust and information sharing, two important interrelationships directly related to information technology. Blockchain technology can serve as a convenient intermediary for relationships between firms that are not yet established or run at high costs due to a lack of trust [19]. Blockchain technology can also provide greater visibility across all supply chains [18].

Blockchain technology has changed the way the administrative control mechanism is regulated and maintained digitally. In the blockchain, data are transformed into digital codes, stored in shared databases, have a higher transparency, and the risk of deletion and revision is limited. The secret power of the blockchain lies in every deal, payment, and all kinds of commercial and interactive activities with digital recording. With blockchain technology, trust is shifted to computer codes by disabling human and traditional intermediaries in verifying transactions [20]. When multiple changes are made simultaneously on multiple computers, it eliminates the possibility of conflicting versions of the same data in a distributed database. Both distributed databases and blockchains use multiple computers for operations and administrative procedures can be compared. Banking is primarily conducted through physical letters of credit, and the intermediaries used ensure the global economy's flow. Due to global financial crises, financial supply chains need to be redesigned in the banking sector [21]. Blockchain technology can revolutionize the global supply platform by replacing intermediaries and eliminating paperwork.

\subsection{Blockchain Technology and Supply Chain Transparency}

Transparency is defined as the most straightforward and transparent circulation of information inside and outside the company. It is the timely and complete disclosure of all information regarding transactions to all stakeholders [22]. It is also related to outsiders' perception of the working system [23]. In a broad sense, transparency refers to the openness of information in a way that makes it easier to see what actions have been or are being performed [24].

Transparency is a term that addresses the overall visibility of the supply chain. The transparency of a supply chain is the measure for all stakeholders to access, in a common understanding, information about the product they request and to see and acquire it without delay, or a loss [25]. Transparency in the supply chain is primarily based on information about products moving along the chain. Firms develop the ability to proactively communicate with their stakeholders to gain visibility and traceability in supply chain operations [26]. Thus, they ensure the visibility and accessibility of information about products, services, financing, and information flow from the manufacturer to the customer [27]. In this way, stakeholder feedback can be included in the chain to improve supply chain performance. Furthermore, product history can be traced throughout the supply chain, and a clear picture of current activities can be shown. Companies can reduce uncertainty in the public markets by articulating core values to face environmental or social issues by being transparent [28].

Transparency provides ways to reduce the risk for supply chain members by allowing full-time tracking of products in the supply chain [29]. Companies must provide transparency to regain customers' trust and better ideas and impressions of the manufacturer's supply chain violations and understand its product's attention and value and how environmental conditions may affect a product [30]. Transparency in a supply chain increases customer satisfaction and guides companies by providing quality feedback, growing sales, and creating more effective initiatives. In this way, it is known where the products are produced, processed, and by which route they are delivered [31].

Supply chain transparency can facilitate voluntary ethical code (formal) commitments (i.e., laws and ethical sourcing standards). It is asserted to be critical; companies cannot offer transparency in supply chains because supply chains tend to be neglected [32]. 
Many stakeholders have high hopes for blockchain due to its new features such as real-time information sharing, security, accountability, immutability, and transparency [33]. With its proof-of-work and distributed database structure, blockchain technology allows transparency to be improved. Using real-time distributed data sharing enables stakeholders to identify quality, location, transaction, and procedural data [23]. Transparency and reliability are obtained through a series of linked blocks that can be tracked on the blockchain. Each block has a separate ID, and the hash of the previous block is found in the blockchain. These use cases of blockchain enable product tracking, allow full product verification and product authorization throughout the entire transactions, and provide end-to-to-end audits based on permissions throughout the organization [34]. Blockchain reduces opportunistic behavior among trading partners in information tampering, corruption, fraud, and deception. Blockchain provides transparency in transactions between trading partners, thereby instilling and increasing trust [35]. Blockchain accelerates product and transaction transparency by developing an effective tool for strategic planning and better relationships between suppliers, customers, outsourcing, 3PL, and subcontractors [33]. It can change the supply chain into being more efficient and transparent [15].

Transparency in the supply chains, which depends on the use of blockchain technology, is also crucial, because trust in supply chain actors is typically low due to the supply chain's multi-tier nature [36]. Blockchain technology can help build trust and reputation by bringing transparency into the supply chain. A large-scale blockchain solution is capable of completely reworking an entire network's reputation management and detecting fraud. The blockchain consensus provides a strong foundation for the unity of perspective and the ability to achieve greater transparency. Establishing a decentralized supply chain based on blockchain technology instead of a centralized one is significantly more efficient and transparent [37].

Blockchain solves two main issues in the supply chain based on transparency, traceability, and transaction data irreversibility. These two issues are (1) difficulty and inadequacy to prove and claim responsibility due to insufficient information transparency; and (2) counterfeit and inferior quality products that cannot be eliminated due to the multi-zone and long-term characteristics of logistics [38].

Blockchain allows for better tracking and reporting, and transparency in logistics, resulting in improved delivery timelines. With a wide distribution of supply, there is an increased risk of conflict, mismatch, and inconsistency in the traditional supply chains. Blockchain technology is helpful in this context. GPS-based vehicle tracking devices can be used with blockchain. Such devices can provide data for the Blockchain, and these data cannot be overwritten. Blockchain is great for logistics when vehicle location tracking is involved because it reduces costs and increases efficiency. [35].

Blockchain technology offers great potential for the manufacturing industry. It provides a guaranteed degree of security, transparency, and stability that no central data storage technology can provide. In terms of the criteria examined, blockchain can outperform traditional, centralized solutions and offer promising results, especially in terms of organizational and economic criteria [39].

Therefore, the following hypothesis has been formed:

Hypothesis 1 (H1). Blockchain technology utilization significantly affects supply chain transparency.

\subsection{Blockchain Technology and Supply Chain Flexibility}

Contemporary supply chains operate in a more complex, dynamic, and uncertain business environment than ever before. Exaggerated customer expectations of product diversity have shortened product life cycles, and variable demand calls for flexibility in supply chains to necessitate improvement. Supply chain flexibility allows the company and its supply structures, processes, resources, and management systems to adapt to changes in the environment [40]. 
Flexibility may be defined as an ability to meet and respond to diverse customer needs to gain a competitive advantage [41]. Continuously changing to highly ambiguous situations is seen as a major factor in business/industry. Governments can also utilize flexibility in the field of information to adapt and respond quickly to change due to the absence of good information [42]. Creating a flexible supply chain is key to achieving a sustainable competitive advantage in today's environment, characterized by dynamism, uncertainty, and unpredictability [43]. A flexible supply chain improves the delivery process and quickly transports products to market in required quantities [44]. It is one of the prime mechanisms to handle the challenging environment in today's world, where business transactions are becoming more volatile and global. Flexibility is achieved when a firm can effectively respond to and adapt to disruptions and demand changes across the entire supply chain against its competitors to meet customer needs. Rapid economic and technological development calls for increased flexibility in both the internal (marketing and manufacturing) and external (supply and distribution) supply chains [41]. Companies with flexible supply chains can respond faster in uncertain situations and improve their ability to present their products and services quickly and effectively [45].

In the globalizing world, competition has expanded across the entire supply chain, not just on a company basis. Therefore, supply chain members need to restructure themselves to balance their organizations' responsiveness with the market changes by increasing their flexibility [46]. In today's economic environment, firms outsource some of their business processes to ensure supply chain flexibility, which often results in the loss of control and visibility of various logistics operations. Thanks to digital technologies, the visibility of integrated transportation and logistics systems will be achieved at all goods delivery stages, from manufacturers to end-users [47]. Firms need to share information directly to be immediately applied to each firm in the chain to provide supply chain flexibility. Different information is needed to ensure that the chain can act as a whole. Therefore, information transferred from one organization to another should be helpful and simultaneously available to other parties in the chain [48].

Blockchain technology is suited to serve customers by facilitating tracking and tracing the various stages of an order's production to delivery and adjusting quickly. The applications brought by blockchain technology can only be realized at specific contact points in the network with all relevant parties' acceptance. Thus, data security can be controlled for all supply chain transactions [49]. Blockchain can increase supply chain visibility and enable real-time data sharing on the network. Thus, it can support supply chain flexibility strategies by reducing the number of stakeholders affected by an outage [19]. Blockchain can rapidly integrate all supply chain processes. Blockchain technology can improve predictions and manage demand, leading to a more realistic supply and inventory management. Furthermore, blockchain can enable all design-related documents to be shared and used. Thus, improved decision-making is available throughout the supply chain, because quality documents can be provided to all participants [35].

Therefore, the following hypothesis has been formed:

Hypothesis 2 (H2). Blockchain technology utilization significantly affects supply chain flexibility.

\subsection{Blockchain Technology and Trust in the Supply Chain}

As trade/industry networks become more complex in modern societies, firms in the network may be forced to interact with other companies they do not know [50]. Trust between firms is crucial to the supply chain's success, and optimum information sharing is necessary to ensure trust. Every stakeholder in the supply chain seeks power and wants to avoid uncertainty risks by sharing information, thus tackling ethical non-compliance, lack of communication, and infidelity [15]. In order to lower the possibility of trust being damaged in the supply chain, connectivity and vulnerabilities must be identified and assessed. The first step in the risk assessment process is to identify the supply chain partners. Next, a supply chain map showing the relevant information flows is created. 
Identifying these flows (e.g., freight, containers, capital, documents) helps to predict potential bottlenecks and the risk and attack levels, including possible failures due to cyber threats [51].

Many factors drive blockchain technology for information sharing in the supply chain, but trust development is one of the most important [52]. In a blockchain, all transactions are logged in a timestamped, observable manner, and confirmed. Thus, transactions cannot be changed or deleted once all relevant parties approve them. Regarding data integrity and security, it has the following characteristics: more security, traceability, efficiency, and transparency in supply chain transactions can be obtained through the use of blockchain technology [3]. Records cannot be changed on the blockchain, meaning all supply chain members' transactions and decisions are recorded and documented on the blockchain. All supply chain members are permanently aware of the accuracy of these transactions. In addition, when firms' activities lead to controversial business results, supply chain members monitor them and take this into account in their decisions and adjust their activities accordingly when finalizing future transactions [53].

Another factor that creates trust in the supply chain is smart contracts that can be used with blockchain technology. Blockchain applications and smart contracts can be used in various areas, from insurance returns to financial transactions, corporate transactions, traceability of products, and intellectual property protection. For this reason, the number of blockchain and smart contract applications gradually continues to increase [54]. Smart contracts can be applied in short supply chains with multiple tiers of suppliers and subcontractors. Automation can deliver accepted contracts to specified parties, application upgrades based on agreed changes, vent occurrences, and copyright submissions [55]. When a smart contract is invoked, nodes in the blockchain run it locally with parameters. The result is accepted and added to the blockchain if it can be mutually verified [56]. A smart contract is a well-defined and unchanging program. All the shared ledger transactions must follow strict procedures before they are posted (database log) [11]. A smart contract is a script which has been registered on a blockchain. Once this file has been submitted through the blockchain and validated, predefined transactions will be executed. The terms of a smart contract are published on the blockchain; therefore, all parties can be assured that the contract will always be executed as agreed, meaning that there are fewer trust issues to contend [57].

Blockchain improves operations in many areas of a firm, including the supply chain, through secure data exchange in a distributed manner. The adoption of blockchain technology can also increase the trust of the customer. It ensures trust throughout the supply chain and, therefore, improves the entire supply chain's performance [15]. Blockchain technology features such as reliability, traceability, and data accuracy mean less need for intermediaries that cause insecure environments [58]. The use of blockchain enables end-to-end data calibration across various supply chains, increases the security of stored data, and ensures the real-time acquisition of all information [34]. The incorporation of blockchain technology enables monitoring of individual suppliers' compliance status while assuring security for sensitive documents [59]. Reliability in supply chain functions and practices such as close relationships with suppliers and customers, outsourcing, and just-in-time procurement, can be improved with Blockchain [33]. Three levels of security are incorporated into the blockchain system. Decentralization ensures that data will not be changed in any way. Secondly, cryptographic technology secures data security while also ensuring that data cannot be altered without knowing the correct secret key. Consensus protocols protect the entire network by requiring that all nodes have uniform protocols [60].

Conflicting goals between buyers and suppliers in the supply chain is a factor that negatively affects the trust in supply chains. If blockchains are used to record supply chain data without errors, the relevant supply chain members will be held accountable, and disclosure issues will be resolved. The negative impact of conflicting objectives will be minimized, increasing trust in supply chains [17]. 
Blockchain technology ensures that all transaction data can be accessed at any time and from anywhere. Each event log creates an automatic proof of each block's history, location, and ownership in the chain. Each firm in the blockchain technology network maintains the database or ledger's security and integrity, because data previously entered on the Blockchain can neither be deleted nor changed [61]. Thus, a more secure data process will increase consumers' trust and confidence in transactions throughout the supply chain. Business transactions often involve sensitive business information; therefore, faith and trust in data sharing are crucial for supply chain actors.

In contrast to public blockchains, permissioned blockchains grant greater privacy, auditability, and administrative efficiency. The blockchain-based system also maintains data integrity and security. A blockchain will serve as a better solution to data management, because it will be resistant to this kind of attack. The distributed ledger technology of blockchain provides highly secure and unchanging supply chain data [55].

Therefore, the following hypothesis has been formed:

Hypothesis 3 (H3). Blockchain technology utilization significantly affects supply chain trust.

The research model in which research hypotheses are shown is displayed in Figure 1.

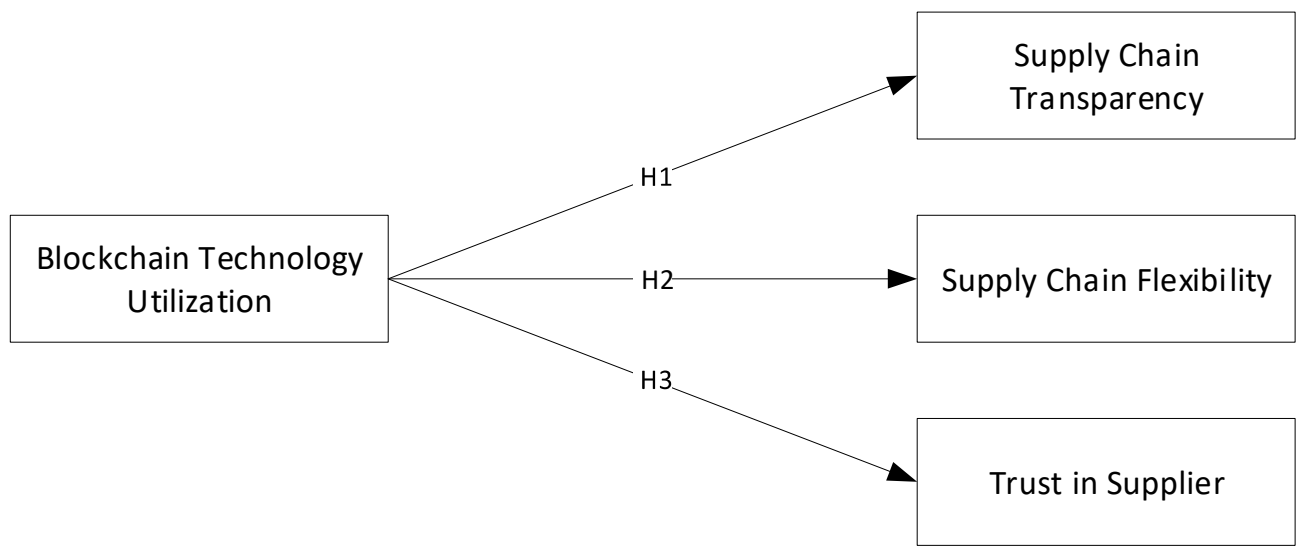

Figure 1. Research model.

\section{Materials and Methods}

\subsection{Sample and Data Collection}

The empirical analysis used data obtained from 84 companies that are listed in the first 1000 exporting firms declared in 2019 by the Turkey Exporters Assembly. Before collecting survey data, we interviewed companies in various ways (face to face, mail, phone) and asked if they were using blockchain technology and would like to participate in our study. Blockchain is a technology that is still in widespread use; therefore, we did not expect the sample size to be very large. As a result of our interviews, 88 companies stated that they used the technology and wanted to participate in the study. We launched a survey application in November 2020 and collected data by sending the questionnaire via email from these 88 companies through surveys. Four of the questionnaires we obtained were not suitable for analysis; therefore, we removed them from the dataset, and thus the sample of our study consisted of 84 companies. Although this sample size is small, we believe that the research sample is homogeneous in terms of sectors. Sectoral information of the companies participating in the study is shown in Table 1, which is based on statements from the companies. 
Table 1. Sectoral information.

\begin{tabular}{ccc}
\hline Sector & Frequency & $\%$ \\
\hline Packaging & 9 & 10.7 \\
Recycling & 1 & 1.2 \\
Pine & 2 & 2.4 \\
Environmental Technologies & 1 & 1.2 \\
Durable Goods & 1 & 1.2 \\
Iron and Steel & 1 & 1.2 \\
Electric-Electronic & 2 & 2.4 \\
Industrial Kitchen & 2 & 2.4 \\
Food & 18 & 21.4 \\
Carpet & 2 & 2.4 \\
Non-Durable Goods & 4 & 4.8 \\
Building & 3 & 3.6 \\
Paper & 1 & 1.2 \\
Chemistry & 4 & 4.8 \\
Machine & 2 & 2.4 \\
Printing Press & 2 & 2.4 \\
Furniture & 3 & 3.6 \\
Forest Products & 1 & 1.2 \\
Automotive & 1 & 1.2 \\
Petrochemical & 3 & 3.6 \\
Health & 4 & 4.8 \\
Solar Energy & 1 & 1.2 \\
Textile & 9 & 10.7 \\
Telecommunication & 1 & 1.2 \\
Cleaning & 6 & 7.1 \\
Total & 84 & 100.0 \\
\hline
\end{tabular}

\subsection{Measurement Instrument}

The questionnaire used in the study consisted of 2 parts; the first part included questions about some demographic characteristics of the participating companies. In the second part, there were research questions to measure blockchain technology utilization (BTU), supply chain transparency (SCT), supply chain flexibility (SCF), and trust in supplier (TIS) variables, on a 1-5 Likert scale, with informants asked to indicate their degree of agreement with statements (1-strongly disagree, 3 -neither agree nor disagree and 5 strongly agree). The questionnaire was adopted from the studies listed below to measure four variables (see Appendix A):

1. Blockchain technology utilization (BTU); Zelbst et al. (2019) [29]; based on seven items;

2. Supply chain transparency (SCT); Zelbst et al. (2019) [29]; based on five items;

3. Supply chain flexibility (SCF); Um et al. (2017) [62]; based on six items;

4. Trust in supplier (TIS); Wang et al. (2014) [63] (two items) and Cho et al. (2018) [64] (three items); based on five items.

\subsection{Analysis Method}

In this study, we investigated the effect of using blockchain technology in manufacturing companies on supply chain flexibility, supply chain transparency, and trust in the supplier. In the analysis of the data, we used the PLS-SEM method, which can be used in such cases and produces consistent results; because the sample size was small, it was not suitable for analysis with other methods. PLS-SEM provides solutions with small sample sizes when models contain a large number of constructs and items. Technically, this is accomplished through the use of the PLS-SEM algorithm, which computes measurement and structural model relationships independently of one another, rather than concurrently. Briefly, the algorithm computes partial regression relationships between the 
measurement and structural models via separate ordinary least squares regressions, as the name implies [65].

\section{Results}

The analysis of the study started with testing the validity and reliability of the measurement instrument. By creating a measurement model to test the questionnaire's validity and reliability in the Smart-PLS program, internal consistency reliability, convergence validity, and dissociation validity coefficients were examined. In determining the internal consistency reliability, composite reliability (CR) coefficients were calculated. In investigating the convergent validity, average variance extracted (AVE) values explained with factor loads were used. It was expected that the factor loads were $\geq 0.70$, the combined reliability coefficients were $\geq 0.70$, and the explained average variance value was $\geq 0.50$ [66]. Cronbach's $\alpha$ coefficient was used to evaluate the reliability of the scales separately. A coefficient value of $\geq 0.70$ indicates that the scales are at an acceptable level of reliability. Table 2 shows the validity and reliability results of the measurement model.

Table 2. Measurement model validity and reliability.

\begin{tabular}{|c|c|c|c|c|c|c|}
\hline Variables & Items & $\lambda$ & $\alpha$ & rho_A & CR & AVE \\
\hline \multirow{5}{*}{$\begin{array}{l}\text { Blockchain } \\
\text { Technol- } \\
\text { ogy } \\
\text { Utilization } \\
\text { (BTU) }\end{array}$} & BTU1 & 0.911 & \multirow{5}{*}{0.962} & \multirow{5}{*}{0.964} & \multirow{5}{*}{0.962} & \multirow{5}{*}{0.834} \\
\hline & BTU2 & 0.945 & & & & \\
\hline & BTU4 & 0.830 & & & & \\
\hline & BTU5 & 0.894 & & & & \\
\hline & BTU6 & 0.979 & & & & \\
\hline \multirow{6}{*}{$\begin{array}{l}\text { Supply } \\
\text { Chain } \\
\text { Flexibility } \\
\text { (SCF) }\end{array}$} & SCF1 & 0.912 & \multirow{6}{*}{0.951} & \multirow{6}{*}{0.955} & \multirow{6}{*}{0.947} & \multirow{6}{*}{0.751} \\
\hline & SCF2 & 0.967 & & & & \\
\hline & SCF3 & 0.795 & & & & \\
\hline & SCF4 & 0.756 & & & & \\
\hline & SCF5 & 0.747 & & & & \\
\hline & SCF6 & 0.987 & & & & \\
\hline \multirow{8}{*}{$\begin{array}{l}\text { Supply } \\
\text { Chain } \\
\text { Trans- } \\
\text { parency } \\
\text { (SCT) } \\
\text { Trust in } \\
\text { Supplier } \\
\text { (TIS) }\end{array}$} & SCT2 & 0.835 & \multirow[t]{4}{*}{0.873} & \multirow[t]{4}{*}{0.885} & \multirow[t]{4}{*}{0.867} & \multirow[t]{4}{*}{0.625} \\
\hline & SCT3 & 0.629 & & & & \\
\hline & SCT4 & 0.732 & & & & \\
\hline & SCT5 & 0.934 & & & & \\
\hline & TIS1 & 0.814 & \multirow{4}{*}{0.860} & \multirow{4}{*}{0.876} & \multirow{4}{*}{0.867} & \multirow{4}{*}{0.622} \\
\hline & TIS3 & 0.879 & & & & \\
\hline & TIS4 & 0.790 & & & & \\
\hline & TIS5 & 0.656 & & & & \\
\hline
\end{tabular}

Hair et al. [66] states that factor loads should be $\geq 0.708$. The authors also suggest that expressions with factor loads between 0.40 and 0.70 should be excluded from the model in case of an increase in AVE or CR values. For this reason, the third and the seventh items of the blockchain technology utilization (BTU3), (BTU7), the first item of the supply chain transparency (SCT1), and the second item (TIS2) of the trust in supplier were excluded from the analysis. The calculated AVE and CR values were above the threshold values; therefore, the third item of the supply chain transparency (SCT3) and the fifth item of the trust in supplier (TIS5) were not removed from the scale, with factor loads below 0.708. As a result, $\alpha$ coefficients were obtained between 0.860 and 0.964 , the CR values between 0.867 and 0.962 , and the AVE values between 0.622 and 0.834 . These findings show that the scales meet the conditions for convergence validity.

Fornell and Larcker criteria and heterotrait-monotrait ratios (HTMT criteria) were examined to verify the scale's discriminant validity. Findings regarding the Fornell and Larcker criteria are provided in Table 3. 
Table 3. Discriminant validity (Fornell and Larcker criteria).

\begin{tabular}{lllll}
\hline & BTU & SCF & SCT & TIS \\
\hline BTU & 0.913 & & & \\
SCF & 0.422 & 0.866 & & \\
SCT & 0.490 & 0.502 & 0.791 & 0.789 \\
TIS & 0.441 & 0.579 & 0.592 & \\
\hline
\end{tabular}

According to Fornell and Larcker [67], the AVE values' square root should be higher than the correlations between the structures included in the study. When Table 3 is examined, it is seen that the square root of the AVE values of each latent variable is greater than the correlation coefficients of the variables, which means that the model meets the Fornell-Larcker criterion for discriminant validity.

Findings regarding the HTMT criteria are given in Table 4.

Table 4. Discriminant validity (heterotrait-monotrait ratio).

\begin{tabular}{ccccc}
\hline & BTU & SCF & SCT & TIS \\
\hline BTU & & & & \\
SCF & 0.414 & & & \\
SCT & 0.482 & 0.490 & & \\
TIS & 0.445 & 0.589 & 0.604 & \\
\hline
\end{tabular}

The HTMT criterion proposed by Henseler, Ringle, and Sarstedt [68] expresses the ratio of the average correlations of the expressions of all variables in the study to the geometric means of the correlations of the expressions of the same variable. The authors stated that if the structures to be measured are theoretically close to each other, the HTMT coefficient should be below 0.90 . If they are theoretically distant from each other, it should be below 0.85 . When Table 4 is examined, it can be observed that HTMT coefficients were realized below the threshold values.

Before analyzing the structural equation model, correlation analysis was conducted to assess the direction and severity of the relationship between variables. Analysis results are given in Table 5.

Table 5. Correlation analysis.

\begin{tabular}{ccccccccc}
\hline & Mean & Std. Dev. & \multicolumn{2}{l}{ Skewness Kurtosis } & BTU & SCT & SCF & ST \\
\hline BTU & 3.2548 & 1.16468 & -0.578 & -0.573 & 1 & & & \\
SCT & 3.4375 & 0.87886 & -0.304 & 0.002 & $0.446^{* *}$ & 1 & & \\
SCF & 3.2937 & 1.09233 & -0.322 & -0.782 & $0.397^{* *}$ & $0.451^{* *}$ & 1 & \\
TIS & 3.8601 & 0.75983 & -0.039 & -0.568 & $0.402^{* *}$ & $0.527^{* *}$ & $0.542^{* *}$ & 1 \\
${ }^{* * *} p<0.001{ }^{* *} p<0.05^{*} p<0.10$. & & & & &
\end{tabular}

Correlation analysis results showed that there was a significant relationship between the variables in the same direction at the level of 0.01 significance. Additionally, skewness and kurtosis values were found to be between -2 and +2 . This finding shows that the scales had a normal distribution.

The structural equation model is given in Figure 2. 


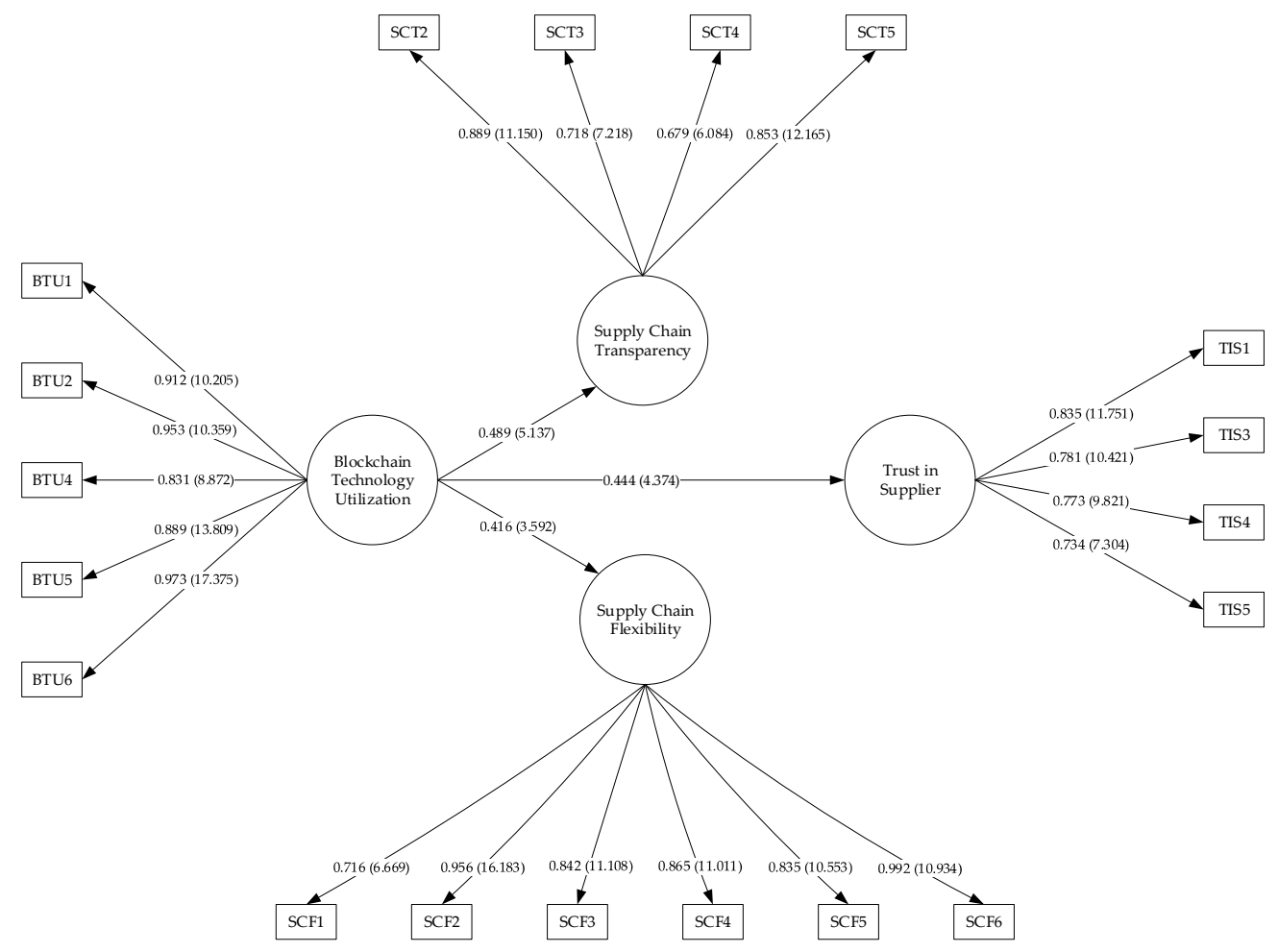

Figure 2. Structural equation model.

Some other values that are important in evaluating the model need to be checked. The model's explanatory power $\left(\mathrm{R}^{2}\right)$, estimation fit $\left(\mathrm{Q}^{2}\right)$, and $\mathrm{F}^{2}$ value indicate the effect size. Research model coefficients are given in Table 6.

Table 6. Research model coefficients.

\begin{tabular}{ccccccc}
\hline \multicolumn{2}{c}{ Variables } & VIF & $\mathbf{R}^{2}$ & $\mathbf{F}^{\mathbf{2}}$ & $\mathbf{Q}^{\mathbf{2}}$ \\
\hline \multirow{3}{*}{ BTU } & SCF & 1.00 & 0.178 & 0.216 & 0.123 \\
\cline { 2 - 6 } & & SCT & 1.00 & 0.240 & 0.317 & 0.125 \\
\cline { 2 - 6 } & TIS & 1.00 & 0.194 & 0.241 & 0.107 \\
\hline
\end{tabular}

When the $\mathrm{R}^{2}$ values are examined, it can be seen that $17.8 \%$ of the use of blockchain technology is explained by supply chain flexibility, $24 \%$ by supply chain transparency, and $19.4 \%$ by the trust in supplier. The model's prediction power for the endogenous variables could be explained in the structural model, calculated by blindfolding analysis. As a result of the analysis, the predictive power coefficient $\left(\mathrm{Q}^{2}\right)$ was more significant than zero, indicating that the model could predict endogenous variables [66]. For $\mathrm{F}^{2}$ values, 0.02 is considered weak, 0.05 medium, and above 0.7 high [69]. In the research model, $\mathrm{F}^{2}$ values were determined at a medium level. According to Hair et al. [66], the VIF (variance inflation factor) coefficients should be below the threshold value of five to avoid collinearity problems among the variables. VIF coefficients were below five; therefore, it could be confirmed that there was no collinearity problem between variables.

The impact coefficients of the research model are given in Table 7. 
Table 7. Research model coefficients.

\begin{tabular}{cccccc}
\hline Variables & $\boldsymbol{\beta}$ & Standard Dev. & T Stat. & $\boldsymbol{p}$-Values & Conf. Int. \\
\hline BTU $\rightarrow$ SCF & 0.420 & 0.116 & 3.595 & 0.000 & $0.182-0.634$ \\
BTU $\rightarrow$ SCT & 0.496 & 0.097 & 5.029 & 0.000 & $0.296-0.677$ \\
BTU $\rightarrow$ TIS & 0.447 & 0.103 & 4.296 & 0.000 & $0.224-0.636$ \\
\hline
\end{tabular}

As a result of the analysis, it was found that blockchain technology utilization significantly affects supply chain flexibility and transparency. It has also been found that the use of blockchain technology positively affects the trust of suppliers. The fact that $T$ values were obtained above 1.96 and that the confidence interval's lower and upper values did not include zero values support the significant effect. As a result of the analysis, the H1, $\mathrm{H} 2$, and $\mathrm{H} 3$ hypotheses were supported.

\section{Discussion: Blockchain Technology and Supply Chain Integration in Terms of Supply Chain Dynamics}

In all their operations, companies first try to plan how they can cope with uncertainty and risks. Moreover, they are aware of the new opportunities they can seize, thanks to their information. Businesses that can plan their operating cycles with maximum consistency in the market anticipate the negativities they may encounter and take a proactive approach to gain a sustainable competitive advantage and continue their existence in this way. Therefore, it is an indisputable fact that information is vital to a business. At this point, blockchain technology is seen as an opportunity to process data and information, which are some of the most important assets of companies, more effectively, and to store them in a more robust security system with reduced costs. The fact that interconnectedness has increased considerably thanks to digital technologies can improve cooperation and integration in supply chains. It is also a separate issue to protect this commitment against malicious initiatives.

In this context, the idea that blockchain technology can benefit companies motivated us to do this research. In this study, we wanted to investigate how transparency, flexibility, and trust, which are among the main requirements of conducting a more efficient supply chain process, will be affected by new information technologies. We think that these dynamics will increase the level of cooperation and integration in supply chains. The more supply chain stakeholders can trust each other, the more information they can share, the more information they share, a more transparent supply chain can be formed, and better integration can be achieved. The level of cooperation can increase, and thus the flexibility of the supply chain can increase.

The first finding of the research was that blockchain technology would increase supply chain transparency. This finding coincides with the findings in the literature [15,33-35]. Transparency is one of the most critical problems in supply chains in effective and robust cooperation and integration. It is stated in the literature that transparency enables proactive communication and collaboration in supply chains [26], providing visibility of product flow to customers [27]. Thus, stakeholder feedback is included in the chain more effectively [28]. Increasing stakeholders' role in the processes can help companies carry out more effective open-innovation activities [70]. Concurrently, transparency can contribute to improving companies' customer-involved product design processes. Enhancing product design processes enables companies to gain a sustainable competitive advantage [71]. Therefore, companies should take advantage of blockchain technology to increase transparency in their supply chains.

Secondly, we found that blockchain technology increases supply chain flexibility. More flexible supply chains can better meet customer demands [41] and better tackle the volatile and uncertain environments [43]. Real-time data sharing will be enabled in supply chains using blockchain technology [19]. The business environment is more complicated than ever; therefore, blockchains are being used to rapidly integrate all of the supply chain processes. Decision processes such as demand forecasting, inventory management [35], 
and determination of key performance indicators [72] can be made more efficient and have a positive impact on a company's sustainability.

The third finding of the research showed us that blockchain technology is a useful tool to build trust in supply chains. Inter-firm trust is crucial for the success of supply chains [15] because effective collaboration which improves sustainability performance requires a high level of information sharing [73] and trust in each other [52]. Especially in cases of outsourcing, such as $3 \mathrm{PL}$, companies have to earn trust based on trust. This finding of our study confirms similar results in the literature $[15,33,34,58-60]$. Firms have to build trust to increase collaboration and integration. Therefore, companies can benefit from blockchain technology in both establishing and maintaining trust.

\section{Conclusions}

Blockchain technology is perhaps one of the concepts which are most prevailing today. With digitalization becoming an ordinary (even necessary) phenomenon, we have started to digitize our assets. We call digitalization the transformation of facts into ones and zeros (data) that can be stored, transferred, analyzed in a computer environment. We have started to explore ways to protect all the assets that we can digitize (convert into data) with this technology. Therefore, blockchain technology was first developed to ensure digital asset security (i.e., cryptocurrency).

In this study, the effect of blockchain technology utilization on supply chain flexibility, transparency, and trust has been investigated. Blockchain technology is approached with suspicion because it is very new and not known by companies. Therefore, companies can see their investments in this technology as huge risks. In this research, we tried to reveal some of the benefits that the technology in question can provide to companies. For this purpose, we determined transparency, flexibility, and trust, which are important issues for supply chains, as dependent variables of the research.

As a result of our analysis, we found that blockchain technology utilization significantly affects transparency, flexibility, and trust in supply chains. The relevant literature emphasizes that companies can increase customer satisfaction, and consequently customer loyalty, by providing more transparent supply chain processes. Moreover, supply chain transparency can improve the level of supply chain cooperation by increasing trust between companies. Additionally, supply chain flexibility can be an essential tool for companies to gain a sustainable competitive advantage. According to the research results, blockchain is an important and valuable technology in terms of all three variables. We believe that this research will help companies alleviate their doubts about blockchain technology.

In the literature review, conducted at the beginning of this study, we could not find a study examining blockchain technology in the context of the abovementioned supply chain dynamics. In this respect, we believe that the research model established in our research is original, and we hope that this study will be an essential contribution to the existing literature. We also believe that the findings of the study will benefit all manufacturing companies.

We can state the following about the study's limitations and further research: This study's first limitation is that sample frame and size. We collected data from the companies listed in the first 1000 exporting firms declared in 2019 by the Turkey Exporters Assembly. In the research, we only collected data from companies using blockchain technology to ensure irrelevancy. Therefore, we could not increase the sample size more. When this technology becomes more widespread in the future, studies with larger samples should be carried out. Moreover, carrying out similar studies on companies with headquarters in other countries may contribute to better understanding the issue and performing comparisons between countries.

Furthermore, we acknowledge the high variability in responses among companies in the study. Thirdly, this research focused on manufacturing companies. For future research, it is proposed to conduct studies that focus on all types of companies. It is recommended to test the current research model, especially in the maritime transport sector, where 
blockchain technology is important. Additionally, in this study, the PLS-SEM method was used to analyze the data. The reason for using this method was that the number of samples could not provide the required sufficiency in other SEM methods. However, in other studies, the re-examination of the same variables with data mining methods, such as clustering techniques and support vector machines, will contribute further to the literature (for methodological information, see Alkahtani et al. [74]). Finally, in this study, there is an indirect reference to cooperation and integration in supply chains. In future research, it is recommended to examine the variables of cooperation and integration that were not included in the model of this research by directly incorporating them into research models. It is also considered that examining the regulatory effect of advanced technology usage policies is very important in terms of the relevant literature.

Author Contributions: Conceptualization, B.Y. and I.M.-K.; methodology, B.Y.; software, Ş.Ç.; validation, I.M.-K., Ş.Ç. and R.Č.; formal analysis, B.Y.; investigation, I.M.-K.; resources, Ş.Ç. and R.Č.; data curation, B.Y.; writing-original draft preparation, B.Y.; writing-review and editing, I.M.-K. and R.Č.; visualization, R.Č.; supervision I.M.-K. All authors have read and agreed to the published version of the manuscript.

Funding: This research received no external funding.

Institutional Review Board Statement: Not applicable.

Informed Consent Statement: Not applicable.

Data Availability Statement: The data of this study are available from the authors upon request.

Conflicts of Interest: The authors declare no conflict of interest.

\section{Appendix A}

Table A1. Measurement instrument.

\begin{tabular}{|c|c|c|}
\hline & & Blockchain Technology Utilization \\
\hline \multirow{7}{*}{ Zelbst et al. (2019) [29] } & BTU1 & $\begin{array}{l}\text { We use blockchain technology to securely record transaction data as products move } \\
\text { through the supply chain }\end{array}$ \\
\hline & BTU2 & $\begin{array}{l}\text { We use blockchain technology to reduce the amount of time required to complete complex } \\
\text { transactions with our supply chain partners }\end{array}$ \\
\hline & BTU3 & $\begin{array}{l}\text { We use blockchain technology to reduce the costs associated with resolving complex } \\
\text { transactions with our supply chain partners }\end{array}$ \\
\hline & BTU4 & We use blockchain technology to enhance privacy \\
\hline & BTU5 & We use blockchain technology to improve auditability \\
\hline & BTU6 & We use blockchain technology to increase operational efficiency \\
\hline & BTU7 & $\begin{array}{l}\text { We use blockchain to improve the security of our information systems used to share } \\
\text { information among our supply chain partners }\end{array}$ \\
\hline \multirow{6}{*}{ Zelbst et al. (2019) [29] } & & Supply Chain Transparency \\
\hline & SCT1 & $\begin{array}{l}\text { We have mapped our supply chain and provide the mapping information to our supply } \\
\text { chain partners and our customers }\end{array}$ \\
\hline & SCT2 & $\begin{array}{l}\text { Material flows from our suppliers have been mapped and related information is available } \\
\text { for our supply chain partners and customers to view }\end{array}$ \\
\hline & SCT3 & $\begin{array}{l}\text { We provide our supply chain partners and our customers with information that allows } \\
\text { them to easily determine the specific materials used to make our products and where } \\
\text { those materials are produced }\end{array}$ \\
\hline & SCT4 & $\begin{array}{l}\text { We provide our supply chain partners and our customers with information that allows } \\
\text { them to easily determine where materials used in our products originated }\end{array}$ \\
\hline & SCT5 & $\begin{array}{l}\text { We provide our supply chain partners and our customers with information that proves } \\
\text { that the materials used to produce our products are responsibly and sustainably sourced } \\
\text { or produced }\end{array}$ \\
\hline
\end{tabular}


Table A1. Cont.

\begin{tabular}{lll}
\hline & \multicolumn{3}{c}{ Blockchain Technology Utilization } \\
\hline & & Supply Chain Flexibility \\
\cline { 2 - 3 } & SCF1 & Changes in the quantity of orders to suppliers \\
\cline { 2 - 3 } Um et al. (2017) [62] & SCF2 & Changes in times of orders placed with suppliers \\
\cline { 2 - 3 } & SCF4 & Changes in production volume \\
\cline { 2 - 3 } & SCF5 & Implement engineering change orders in production \\
\cline { 2 - 3 } Wang et al. (2014) [63] & SCF6 & Alter delivery schedules to meet changing customer requirements \\
\cline { 2 - 3 } & & Trust in Supplier \\
\hline \multirow{3}{*}{ Cho et al. (2018) [64] } & TIS1 & Whenever the major supplier gives us advice on our business operations, we know that \\
& they are sharing their best judgment \\
\cline { 2 - 3 } & TIS3 & Our suppliers have been open and honest when dealing with us \\
\cline { 2 - 3 } & TIS4 & Our suppliers respect the confidentiality of the information they receive from us \\
\hline
\end{tabular}

\section{References}

1. Helo, P.; Hao, Y. Blockchains in operations and supply chains: A model and reference implementation. Comput. Ind. Eng. 2019, 136, 242-251. [CrossRef]

2. Heidary Dahooie, J.; Zamani Babgohari, A.; Meidutè-Kavaliauskienè, I.; Govindan, K. Prioritising sustainable supply chain management practices by their impact on multiple interacting barriers. Int. J. Sustain. Dev. World Ecol. 2021, 28, 267-290. [CrossRef]

3. Kamble, S.S.; Gunasekaran, A.; Kumar, V.; Belhadi, A.; Foropon, C. A machine learning based approach for predicting blockchain adoption in supply Chain. Technol. Forecast. Soc. Chang. 2021, 163, 120465. [CrossRef]

4. Dwivedi, S.K.; Amin, R.; Vollala, S. Blockchain based secured information sharing protocol in supply chain management system with key distribution mechanism. J. Inf. Secur. Appl. 2020, 54, 102554. [CrossRef]

5. Chopra, S.; Meindl, P. Supply Chain Management: Strategy, Planning, and Operation, 6th ed.; global edition; Pearson: Boston, MA, USA, 2016; ISBN 978-93-325-4823-7.

6. Hansen, J.V.; Hill, N.C. Control and Audit of Electronic Data Interchange. MIS Q. 1989, 13, 403-413. [CrossRef]

7. Lee, H.; Özer, Ö. Unlocking the Value of RFID. Prod. Oper. Manag. 2007, 16, 40-64. [CrossRef]

8. Ellis, S.; Morris, H.D.; Santagate, J. IoT-enabled analytic applications revolutionize supply chain planning and execution. Int. Data Corp. (IDC) White Pap. 2015, 1-13. Available online: https://www.savi.com/wp-content/uploads/IDC-IoT-enabled-analyticsapplications_final.pdf (accessed on 10 May 2021).

9. Song, J.M.; Sung, J.; Park, T. Applications of Blockchain to Improve Supply Chain Traceability. Procedia Comput. Sci. 2019, 162, 119-122. [CrossRef]

10. Di Vaio, A.; Varriale, L. Blockchain technology in supply chain management for sustainable performance: Evidence from the airport industry. Int. J. Inf. Manag. 2020, 52, 102014. [CrossRef]

11. Agrawal, T.K.; Kumar, V.; Pal, R.; Wang, L.; Chen, Y. Blockchain-based framework for supply chain traceability: A case example of textile and clothing industry. Comput. Ind. Eng. 2021, 154, 107130. [CrossRef]

12. Musigmann, B.; von der Gracht, H.; Hartmann, E. Blockchain Technology in Logistics and Supply Chain Management-A Bibliometric Literature Review From 2016 to January 2020. IEEE Trans. Eng. Manag. 2020, 67, 988-1007. [CrossRef]

13. Queiroz, M.M.; Telles, R.; Bonilla, S.H. Blockchain and supply chain management integration: A systematic review of the literature. Supply Chain Manag. Int. J. 2019, 25, 241-254. [CrossRef]

14. Lu, Y. Blockchain and the related issues: A review of current research topics. J. Manag. Anal. 2018, 5, 231-255. [CrossRef]

15. Ghode, D.; Yadav, V.; Jain, R.; Soni, G. Adoption of blockchain in supply chain: An analysis of influencing factors. J. Enterp. Inf. Manag. 2020, 33, 437-456. [CrossRef]

16. Wang, Z.; Wang, T.; Hu, H.; Gong, J.; Ren, X.; Xiao, Q. Blockchain-based framework for improving supply chain traceability and information sharing in precast construction. Autom. Constr. 2020, 111, 103063. [CrossRef]

17. Pournader, M.; Shi, Y.; Seuring, S.; Koh, S.C.L. Blockchain applications in supply chains, transport and logistics: A systematic review of the literature. Int. J. Prod. Res. 2020, 58, 2063-2081. [CrossRef]

18. Queiroz, M.M.; Wamba, S.F.; de Bourmont, M.; Telles, R. Blockchain adoption in operations and supply chain management: Empirical evidence from an emerging economy. Int. J. Prod. Res. 2020, 1-17. [CrossRef]

19. Lohmer, J.; Bugert, N.; Lasch, R. Analysis of resilience strategies and ripple effect in blockchain-coordinated supply chains: An agent-based simulation study. Int. J. Prod. Econ. 2020, 228, 107882. [CrossRef] [PubMed] 
20. Esmaeilian, B.; Sarkis, J.; Lewis, K.; Behdad, S. Blockchain for the future of sustainable supply chain management in Industry 4.0. Resour. Conserv. Recycl. 2020, 163, 105064. [CrossRef]

21. Ferreira, F.A.F.; Meidutè-Kavaliauskienè, I. Toward a sustainable supply chain for social credit: Learning by experience using single-valued neutrosophic sets and fuzzy cognitive maps. Ann. Oper. Res. 2020. [CrossRef]

22. Kumar, N.; Ganguly, K.K. External diffusion of B2B e-procurement and firm financial performance: Role of information transparency and supply chain coordination. J. Enterp. Inf. Manag. 2020. [CrossRef]

23. Qian, X.A.; Papadonikolaki, E. Shifting trust in construction supply chains through blockchain technology. Eng. Constr. Archit. Manag. 2020. [CrossRef]

24. Gold, S.; Heikkurinen, P. Transparency fallacy: Unintended consequences of stakeholder claims on responsibility in supply chains. Account. Audit. Account. J. 2018, 31, 318-337. [CrossRef]

25. Sunny, J.; Undralla, N.; Madhusudanan Pillai, V. Supply chain transparency through blockchain-based traceability: An overview with demonstration. Comput. Ind. Eng. 2020, 150, 106895. [CrossRef]

26. Zhu, S.; Song, J.; Hazen, B.T.; Lee, K.; Cegielski, C. How supply chain analytics enables operational supply chain transparency. Int. J. Phys. Distrib. Logist. Manag. 2018, 48, 47-68. [CrossRef]

27. Modi, D.; Zhao, L. Social media analysis of consumer opinion on apparel supply chain transparency. J. Fash. Mark. Manag. Int. J. 2020. [CrossRef]

28. Morgan, T.R.; Richey Jr, R.G.; Ellinger, A.E. Supplier transparency: Scale development and validation. Int. J. Logist. Manag. 2018, 29, 959-984. [CrossRef]

29. Zelbst, P.J.; Green, K.W.; Sower, V.E.; Bond, P.L. The impact of RFID, IIoT, and Blockchain technologies on supply chain transparency. J. Manuf. Technol. Manag. 2019, 31, 441-457. [CrossRef]

30. Azzi, R.; Chamoun, R.K.; Sokhn, M. The power of a blockchain-based supply chain. Comput. Ind. Eng. 2019, 135, 582-592. [CrossRef]

31. Shoaib, M.; Lim, M.K.; Wang, C. An integrated framework to prioritize blockchain-based supply chain success factors. Ind. Manag. Data Syst. 2020, 120, 2103-2131. [CrossRef]

32. Egels-Zandén, N.; Hulthén, K.; Wulff, G. Trade-offs in supply chain transparency: The case of Nudie Jeans Co. J. Clean. Prod. 2015, 107, 95-104. [CrossRef]

33. Aslam, J.; Saleem, A.; Khan, N.T.; Kim, Y.B. Factors influencing blockchain adoption in supply chain management practices: A study based on the oil industry. J. Innov. Knowl. 2021. [CrossRef]

34. Dutta, P.; Choi, T.-M.; Somani, S.; Butala, R. Blockchain technology in supply chain operations: Applications, challenges and research opportunities. Transp. Res. Part E Logist. Transp. Rev. 2020, 142, 102067. [CrossRef] [PubMed]

35. Sheel, A.; Nath, V. Effect of blockchain technology adoption on supply chain adaptability, agility, alignment and performance. Manag. Res. Rev. 2019. [CrossRef]

36. Wang, Y.; Singgih, M.; Wang, J.; Rit, M. Making sense of blockchain technology: How will it transform supply chains? Int. J. Prod. Econ. 2019, 211, 221-236. [CrossRef]

37. Kamble, S.S.; Gunasekaran, A.; Sharma, R. Modeling the blockchain enabled traceability in agriculture supply chain. Int. J. Inf. Manag. 2020, 52, 101967. [CrossRef]

38. Xia, J.; Yongjun, L. Trust Evaluation Model for Supply Chain Enterprises under Blockchain Environment. In Proceedings of the 2017 7th International Conference on Social Network, Communication and Education (SNCE 2017), Shenyang, China, 28-30 July 2017; pp. 634-638. [CrossRef]

39. Herrgoß, L.; Lohmer, J.; Schneider, G.; Lasch, R. Development and Evaluation of a Blockchain Concept for Production Planning and Control in the Semiconductor Industry. In Proceedings of the 2020 IEEE International Conference on Industrial Engineering and Engineering Management (IEEM), Singapore, 14-17 December 2020; pp. 440-444.

40. Fischer, J.-H.; Thomé, A.M.T.; Scavarda, L.F.; Hellingrath, B.; Martins, R. Development and Application of a Maturity Measurement Framework for Supply Chain Flexibility. Procedia CIRP 2016, 41, 514-519. [CrossRef]

41. Jangga, R.; Ali, N.M.; Ismail, M.; Sahari, N. Effect of Environmental Uncertainty and Supply Chain Flexibility Towards Supply Chain Innovation: An exploratory Study. Procedia Econ. Financ. 2015, 31, 262-268. [CrossRef]

42. Yu, K.; Luo, B.N.; Feng, X.; Liu, J. Supply chain information integration, flexibility, and operational performance: An archival search and content analysis. Int. J. Logist. Manag. 2018, 29, 340-364. [CrossRef]

43. Rojo Gallego Burin, A.; Perez-Arostegui, M.N.; Llorens-Montes, J. Ambidexterity and IT competence can improve supply chain flexibility? A resource orchestration approach. J. Purch. Supply Manag. 2020, 26, 100610. [CrossRef]

44. Delic, M.; Eyers, D.R. The effect of additive manufacturing adoption on supply chain flexibility and performance: An empirical analysis from the automotive industry. Int. J. Prod. Econ. 2020, 228, 107689. [CrossRef]

45. Kumar, P.; Shankar, R.; Yadav, S.S. Flexibility in global supply chain: Modeling the enablers. J. Model. Manag. 2008,3 , $277-297$. [CrossRef]

46. Moon, K.K.-L.; Yi, C.Y.; Ngai, E.W.T. An instrument for measuring supply chain flexibility for the textile and clothing companies. Eur. J. Oper. Res. 2012, 222, 191-203. [CrossRef]

47. Bag, S.; Viktorovich, D.A.; Sahu, A.K.; Sahu, A.K. Barriers to adoption of blockchain technology in green supply chain management. J. Glob. Oper. Strateg. Sourc. 2020, 14, 104-133. [CrossRef]

48. Manders, J.H.M.; Caniels, M.C.J.; Paul, W.T. Supply chain flexibility. Int. J. Logist. Manag. 2017, 28, 964-1026. [CrossRef] 
49. Wang, B.; Luo, W.; Zhang, A.; Tian, Z.; Li, Z. Blockchain-enabled circular supply chain management: A system architecture for fast fashion. Comput. Ind. 2020, 123, 103324. [CrossRef]

50. Xu, P.; Lee, J.; Barth, J.R.; Richey, R.G. Blockchain as supply chain technology: Considering transparency and security. Int. J. Phys. Distrib. Logist. Manag. 2021, 51, 305-324. [CrossRef]

51. Min, H. Blockchain technology for enhancing supply chain resilience. Bus. Horiz. 2019, 62, 35-45. [CrossRef]

52. Batwa, A.; Norrman, A. Blockchain Technology and Trust in Supply Chain Management: A Literature Review and Research Agenda. Oper. Supply Chain Manag. Int. J. 2021, 14, 203-220. [CrossRef]

53. de Giovanni, P. Blockchain and smart contracts in supply chain management: A game theoretic model. Int. J. Prod. Econ. 2020, 228, 107855. [CrossRef]

54. Vacca, A.; Di Sorbo, A.; Visaggio, C.A.; Canfora, G. A systematic literature review of blockchain and smart contract development: Techniques, tools, and open challenges. J. Syst. Softw. 2021, 174, 110891. [CrossRef]

55. Wang, Y.; Han, J.H.; Beynon-Davies, P. Understanding blockchain technology for future supply chains: A systematic literature review and research agenda. Supply Chain Manag. Int. J. 2019. [CrossRef]

56. Xuan, S.; Zheng, L.; Chung, I.; Wang, W.; Man, D.; Du, X.; Yang, W.; Guizani, M. An incentive mechanism for data sharing based on blockchain with smart contracts. Comput. Electr. Eng. 2020, 83, 106587. [CrossRef]

57. Ante, L. Smart contracts on the blockchain-A bibliometric analysis and review. Telemat. Inform. 2021, 57, 101519. [CrossRef]

58. Kouhizadeh, M.; Saberi, S.; Sarkis, J. Blockchain technology and the sustainable supply chain: Theoretically exploring adoption barriers. Int. J. Prod. Econ. 2021, 231, 107831. [CrossRef]

59. Venkatesh, V.G.; Kang, K.; Wang, B.; Zhong, R.Y.; Zhang, A. System architecture for blockchain based transparency of supply chain social sustainability. Robot. Comput. Integr. Manuf. 2020, 63, 101896. [CrossRef]

60. Lim, M.K.; Li, Y.; Wang, C.; Tseng, M.-L. A literature review of blockchain technology applications in supply chains: A comprehensive analysis of themes, methodologies and industries. Comput. Ind. Eng. 2021, 154, 107133. [CrossRef]

61. Rejeb, A.; Keogh, J.G.; Simske, S.J.; Stafford, T.; Treiblmaier, H. Potentials of blockchain technologies for supply chain collaboration: A conceptual framework. Int. J. Logist. Manag. 2021. [CrossRef]

62. Um, J.; Lyons, A.; Lam, H.K.S.; Cheng, T.C.E.; Dominguez-Pery, C. Product variety management and supply chain performance: A capability perspective on their relationships and competitiveness implications. Int. J. Prod. Econ. 2017, 187, 15-26. [CrossRef]

63. Wang, Z.; Ye, F.; Tan, K.H. Effects of managerial ties and trust on supply chain information sharing and supplier opportunism. Int. J. Prod. Res. 2014, 52, 7046-7061. [CrossRef]

64. Cho, M.; Bonn, M.A.; Susskind, A.; Giunipero, L. Restaurant dependence/autonomy in the supply chain and market responsiveness: The moderating roles of information technology adoption and trust. Int. J. Contemp. Hosp. Manag. 2018. [CrossRef]

65. Hair, J.F.; Risher, J.J.; Sarstedt, M.; Ringle, C.M. When to use and how to report the results of PLS-SEM. Eur. Bus. Rev. 2019, 31, 2-24. [CrossRef]

66. Hair, J.F.; Hult, G.T.M.; Ringle, C.; Sarstedt, M. A Primer on Partial Least Squares Structural Equation Modeling (PLS-SEM); SAGE Publications: Thousand Oaks, CA, USA, 2016; ISBN 978-1-4833-7743-8.

67. Fornell, C.; Larcker, D.F. Evaluating Structural Equation Models with Unobservable Variables and Measurement Error. J. Mark. Res. 1981, 18, 39-50. [CrossRef]

68. Henseler, J.; Ringle, C.M.; Sarstedt, M. A new criterion for assessing discriminant validity in variance-based structural equation modeling. J. Acad. Mark. Sci. 2015, 43, 115-135. [CrossRef]

69. Hair, J.F.; Ringle, C.M.; Sarstedt, M. PLS-SEM: Indeed a Silver Bullet. J. Mark. Theory Pract. 2011, 19, 139-152. [CrossRef]

70. Meidute-Kavaliauskiene, I.; Çiğdem, Ş.; Vasiliauskas, A.V.; Yıldız, B. Green Innovation in Environmental Complexity: The Implication of Open Innovation. J. Open Innov. Technol. Mark. Complex. 2021, 7, 107. [CrossRef]

71. Goswami, M.; Daultani, Y.; De, A. Decision modeling and analysis in new product development considering supply chain uncertainties: A multi-functional expert based approach. Expert Syst. Appl. 2021, 166, 114016. [CrossRef]

72. Choudhary, A.; De, A.; Ahmed, K.; Shankar, R. An integrated fuzzy intuitionistic sustainability assessment framework for manufacturing supply chain: A study of UK based firms. Ann. Oper. Res. 2021. Available online: https://link.springer.com/ article/10.1007/s10479-019-03452-3 (accessed on 2 April 2021). [CrossRef]

73. Goswami, M.; De, A.; Habibi, M.K.K.; Daultani, Y. Examining freight performance of third-party logistics providers within the automotive industry in India: An environmental sustainability perspective. Int. J. Prod. Res. 2020, 58, 7565-7592. [CrossRef]

74. Alkahtani, M.; Choudhary, A.; De, A.; Harding, J.A. A decision support system based on ontology and data mining to improve design using warranty data. Comput. Ind. Eng. 2019, 128, 1027-1039. [CrossRef] 